\title{
Electrical Performance of a High Temperature 32-I/O HTCC Alumina Package
}

\author{
Liang-Yu Chen ${ }^{1, a}$, Philip G. Neudeck ${ }^{2, b}$, David J. Spry ${ }^{2, c}$, Glenn M. Beheim²,d, \\ and Gary W. Hunter ${ }^{2, e}$ \\ ${ }^{1}$ Ohio Aerospace Institute/NASA Glenn Research Center, 21000 Brookpark Road \\ Cleveland, Ohio 44135 \\ ${ }^{2}$ NASA Glenn Research Center, 21000 Brookpark Road, Cleveland, Ohio 44135 \\ a Email: Liangyu.chen-1@nasa.gov, b Email: Neudeck@ nasa.gov, ${ }^{c}$ Email: David.j.spry@nasa.gov, \\ ${ }^{\mathrm{d}}$ Email: Glenn.m.beheim@nasa.gov, ${ }^{\mathrm{e}}$ Email: Gary.w.hunter@nasa.gov
}

\begin{abstract}
A high temperature co-fired ceramic (HTCC) alumina material was previously electrically tested at temperatures up to $550{ }^{\circ} \mathrm{C}$, and demonstrated improved dielectric performance at high temperatures compared with the $96 \%$ alumina substrate that we used before, suggesting its potential use for high temperature packaging applications. This paper introduces a prototype 32-I/O (input/output) HTCC alumina package with platinum conductor for $500{ }^{\circ} \mathrm{C}$ low-power silicon carbide (SiC) integrated circuits. The design and electrical performance of this package including parasitic capacitance and parallel conductance of neighboring I/Os from $100 \mathrm{~Hz}$ to $1 \mathrm{MHz}$ in a temperature range from room temperature to $550{ }^{\circ} \mathrm{C}$ are discussed in detail. The parasitic capacitance and parallel conductance of this package in the entire frequency and temperature ranges measured does not exceed $1.5 \mathrm{pF}$ and 0.05 $\mu \mathrm{S}$, respectively. SiC integrated circuits using this package and compatible printed circuit board have been successfully tested at $500{ }^{\circ} \mathrm{C}$ for over 3736 hours continuously, and at $700{ }^{\circ} \mathrm{C}$ for over 140 hours. Some test examples of $\mathrm{SiC}$ integrated circuits with this packaging system are presented. This package is the key to prolonged $\mathrm{T} \geq 500^{\circ} \mathrm{C}$ operational testing of the new generation of $\mathrm{SiC}$ high temperature integrated circuits and other devices currently under development at NASA Glenn Research Center.
\end{abstract}

Keywords: Packaging, high temperature, HTCC, alumina, SiC electronics.

\section{Introduction}

NASA space and aeronautical missions require high-temperature environment operable sensors and electronics for probing the inner solar planets, as well as for in situ monitoring and control of next generation aeronautical engines [1]. Various SiC hightemperature sensors, actuators, and electronics have been demonstrated at temperatures near or above $500^{\circ} \mathrm{C}$, but many of these demonstrations have been limited to short durations less than a few hours. The development of a systematic high-temperature packaging system is essential for both long term testing and beneficial applications of $500^{\circ} \mathrm{C} \mathrm{SiC}$ sensors and integrated circuits. Previously, a 96\% polycrystalline alumina $\left(\mathrm{Al}_{2} \mathrm{O}_{3}\right)$ based prototype packaging system with Au thick-film metallization [2] successfully facilitated long term testing of high temperature silicon carbide ( $\mathrm{SiC}$ ) electronic devices for over 10,000 hours at $500{ }^{\circ} \mathrm{C}$ [3]. However, the $96 \% \mathrm{Al}_{2} \mathrm{O}_{3}$ chip-level packages of this prototype system were not fabricated via an integrated commercial co-fired process, which is more suitable for large scale commercial production. A high temperature co-fired ceramic (HTCC) alumina material was previously electrically tested at temperatures up to $550{ }^{\circ} \mathrm{C}$, and demonstrated better dielectric performance at high temperatures compared with the 96\% alumina substrate used before, suggesting its suitability for high temperature packaging applications [4]. This paper introduces a prototype 32-I/O (input/output) HTCC alumina package with platinum conductor for $500{ }^{\circ} \mathrm{C}$ low power $\mathrm{SiC}$ electronics. Both the design and the electrical performance including DC insulation resistance and $\mathrm{AC}$ parasitic conductance and capacitance between neighboring I/Os of this package are discussed.

\section{Material System}

Compared with 96\% alumina, the dielectric performance of experimentally tested HTCC alumina is superior at elevated temperatures [4]. Overall, the dielectric constant of the HTCC alumina is slightly lower and changes less with temperature. The AC 
conductivity (dielectric loss) of this material is also lower than that of $96 \%$ alumina at temperatures above $200{ }^{\circ} \mathrm{C}$, so it is suitable for high temperature applications. HTCC alumina material systems are usually co-fired with thick-film metallization at temperatures $\sim 1550{ }^{\circ} \mathrm{C}$ in noble gas environments, and more often only metals with low CTE (coefficient of thermal expansion) such as tungsten and molymanganese are used with HTCC alumina. However, these conventional metals/alloys have relatively high electrical resistivity, and low oxidation resistance for long term operation in high temperature air ambient. Platinum (Pt) conductor materials designed for HTCC alumina substrates are more suitable for $500{ }^{\circ} \mathrm{C}$ packaging applications. Aluminum oxide is usually used as the binder for $\mathrm{Pt}$ conductors designed for HTCC alumina substrates. Alumina-alumina bonds at $\mathrm{Pt} /$ substrate interface are expected to be more thermodynamically stable over a wide temperature range compared with glass binder used in standard thick-film materials (usually fired at $850{ }^{\circ} \mathrm{C}$ ). An over-layer of gold, either thin-film or thick-film, on Pt metallization surface was proposed to provide improved material compatibility for gold wire-bonding, as well as gold and gold alloy based dieattach [4].

There are several kinds of high temperature cofired alumina materials available on the market. Based on the measured dielectric properties of previously tested HTCC alumina substrates, a high temperature co-fired material system of $92 \%$ alumina with compatible surface and via Pt conductors [5] was selected for the new 32-I/O prototype package. The relative dielectric constant of this material is 8.4 at room temperature and frequencies at and below $1 \mathrm{MHz}$, it increases more with temperature at lower frequencies to peak value 14.1 at $120 \mathrm{~Hz}$ and $550{ }^{\circ} \mathrm{C}$. The measured AC conductivity of the HTCC alumina is less than $10^{-8} \mathrm{~S} / \mathrm{m}$ at frequencies at and below $10 \mathrm{kHz}$, and $10^{-7} \mathrm{~S} / \mathrm{m}$ at frequencies between $100 \mathrm{kHz}$ to $1 \mathrm{MHz}$ at room temperature. The AC conductivity increases more at higher frequencies reaching $4.3 \times 10^{-}$ ${ }^{6} \mathrm{~S} / \mathrm{m}$ at $1 \mathrm{MHz}$ and $550{ }^{\circ} \mathrm{C}$ [4]. Testing of additional HTCC alumina material compounds is planned for future work in this direction to further optimize substrate/metallizations combination system for 500 ${ }^{\circ} \mathrm{C}$ applications.

\section{Package Design}

This new package is designed for low power low frequency SiC JFET based high temperature ICs intended for prolonged operation around $500{ }^{\circ} \mathrm{C}$. It is a surface-mount package with $32 \mathrm{I} / \mathrm{Os}$, it measures about $27.3 \mathrm{~mm}$ x $27.3 \mathrm{~mm}$ x $2.5 \mathrm{~mm}$ (1.07 in. x 1.07 in. $\mathrm{x} 0.1 \mathrm{in}$ ), lid is $1.02 \mathrm{~mm}$ (40 mil) thick. The Pt surface metallization of the package floor is composed of a central square and four surrounding L-shaped patterns allowing multi-chip mixture with individual substrate bias of up to five separate IC dies in a single package. Pt pads for wire-bonding are electrically connected to the pads on the bottom side of the package through hermetic Pt via. One of the pads at
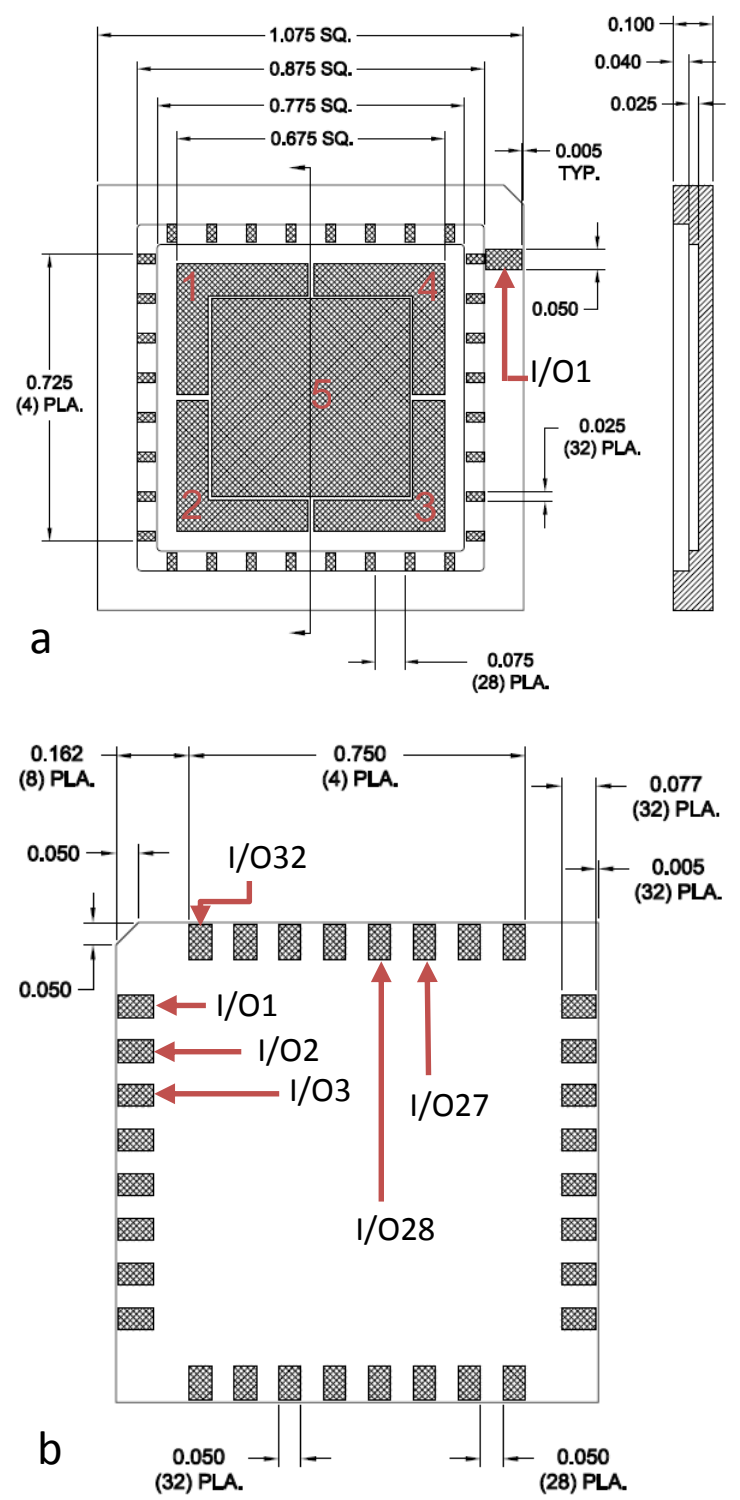

Figure 1: The drawings of 32-pin co-fired Pt/92\% alumina package measured $27.3 \mathrm{~mm} \times 27.3 \mathrm{~mm} \times 2.54$ $\mathrm{mm}$. 1(a) is the top view of the package and 1(b) is the bottom view of the package. All the dimensions are in unit of inch $(1 \mathrm{inch}=25.4 \mathrm{~mm})$. Fig. 1a shows five separate pads on the package floor.

the cut-corner is connected to the pad or ring (two different designs) for connection to the lid 
metallization as the shield. The package design layout shown in Figure 1 has a Pt pad, instead of a ring (not shown), for connection to the lid. The pads on the bottom of the package for surface mount measure 1.27 $\mathrm{mm} \times 2 \mathrm{~mm}$, and the spacing between two neighboring pads at the same edge is $1.27 \mathrm{~mm}$.

\section{Package Characterization}

Temperature dependent electrical parameters of the package, such as parasitic AC conductance and capacitance between the ground $\mathrm{I} / \mathrm{O}(\mathrm{I} / \mathrm{O} 1)$ and its nearest neighbor I/O2, as well as those between I/O2 and $\mathrm{I} / \mathrm{O} 3$ were measured by $\mathrm{AC}$ impedance meters at frequencies of $100 \mathrm{~Hz}, 120 \mathrm{~Hz}, 1 \mathrm{kHz}, 10 \mathrm{kHz}, 100$ $\mathrm{kHz}$, and $1 \mathrm{MHz}$ in a temperature range from room temperature to $550^{\circ} \mathrm{C}$. During the testing, the package was soaked in a temperature-controlled air ambient oven with electrical resistive heating coils embedded through two sidewalls of the chamber. The package was directly connected to $0.25 \mathrm{~mm}$ diameter $\mathrm{Au}$ wires with lengths of approximately $15 \mathrm{~cm}$ which connected to $1 \mathrm{~m}$ long, $50 \Omega \mathrm{RG} 58 \mathrm{C} / \mathrm{U}$ standard coaxial cables located outside of the oven. Agilent 4294A, Keithley 3322, and HP 4192A LCZ impedance meters/analyzer were used to measure the inter I/O AC conductance and capacitance based on a RC parallel circuit model. The AC conductance measures the dielectric loss in the substrate material, and the capacitance measures the dielectric polarization of the substrate materials. DC insulation resistance between two neighboring $\mathrm{I} / \mathrm{Os}$ in a wide range of DC bias up to $50 \mathrm{~V}$ was assessed by the slope of the measured current - voltage (I-V) curve using a Keithley 2400 source / measurement unit (SMU). The package was heated at $550{ }^{\circ} \mathrm{C}$ for 24 hours immediately preceding $\mathrm{AC}$ parameter measurements. Both DC and AC specs of the chip-level packages were measured without package lid. Since the AC parasitic parameters are small and comparable to the contributions from gold wires connecting the package inside the oven to coaxial cables outside the oven leading to the impedance meter/analyzer, the parallel RC parameters between gold wires (without a package) were measured separately and the values were subtracted from those with package for more precise measurement/ assessment of package AC parasitic parameters. At frequency of $1 \mathrm{MHz}$, it became more difficult to compensate the parasitic effects of the wiring in the oven, especially under low package conductance, as shown in Table 1 and 2. For some frequency and temperature combinations, measured $\mathrm{AC}$ conductance is close to the measurement accuracy limit due to the combination of noise level and instrument calibration limit, especially since the part of the circuit wiring was not electro-magnetically shielded from oven heating elements. For these data points only upper limits of measured values are presented. The oven power was briefly switched off during the measurements of data at $120 \mathrm{~Hz}$ to reduce $\mathrm{AC}$ interference from the filaments in the oven.

\subsection{Parasitic AC Parameters}

Table 1 shows the results of parasitic capacitance (upper number) in unit of $\mathrm{pF}$ and parallel AC conductance (lower number) in unit of $\mu \mathrm{S}$ between I/O1 and neighboring I/O2 (see Figure 1b) with I/O1 connected to all of five metallization pads on the package floor using wire-bonding. The measured parasitic capacitance is between $0.3 \mathrm{pF}$ and $1.4 \mathrm{pF}$, generally trending higher at lower frequencies and higher temperatures with the peak capacitance at $120 \mathrm{~Hz}$ and $500^{\circ} \mathrm{C}$ and $550^{\circ} \mathrm{C}$. This trend is consistent with the dependence of dielectric constant of the alumina material on frequency and temperature reported earlier [4]. The capacitances measured at $120 \mathrm{~Hz}$ and $\mathrm{T} \leq 100^{\circ} \mathrm{C}$ seem slightly high. At these frequency and temperature combinations the total impedance is high so the measurement uncertainty of

Table 1: Parasitic capacitance (upper) in unit of $\mathrm{pF}$ and $\mathrm{AC}$ conductance (lower) in unit of $\mu \mathrm{S}$ between I/O1 and I/O2 without a lid on. I/O1 is connected to ground pads. Contributions of gold wires have been subtracted.

\begin{tabular}{|c|c|c|c|c|c|c|c|c|c|c|c|}
\hline $\mathrm{f}(\mathrm{Hz})$ & $\mathrm{T}_{\mathrm{R}}$ & 100 & 150 & 200 & 250 & 300 & 350 & 400 & 450 & 500 & 550 \\
\hline \multirow{2}{*}{120} & 1.0 & 0.7 & 0.6 & 0.4 & 0.3 & 0.5 & 0.4 & 0.6 & 0.7 & 1.4 & 1.4 \\
\hline & $<0.001$ & $<0.001$ & $<0.001$ & $<0.001$ & $<0.001$ & $<0.001$ & $<0.001$ & $<0.001$ & $<0.001$ & 0.001 & $<0.001$ \\
\hline \multirow{2}{*}{$1 \mathrm{~K}$} & 0.4 & 0.2 & 0.5 & 0.5 & 0.3 & 0.4 & 0.5 & 0.5 & 0.5 & 0.5 & 0.4 \\
\hline & $<0.001$ & $<0.001$ & $<0.001$ & $<0.001$ & $<0.001$ & $<0.001$ & $<0.001$ & $<0.001$ & $<0.001$ & $<0.001$ & $<0.001$ \\
\hline \multirow{2}{*}{$10 \mathrm{~K}$} & 0.5 & 0.4 & 0.5 & 0.5 & 0.4 & 0.4 & 0.4 & 0.5 & 0.5 & 0.4 & 0.4 \\
\hline & $<0.001$ & 0.0013 & $<0.001$ & $<0.001$ & $<0.001$ & $<0.001$ & $<0.001$ & 0.003 & $<0.003$ & $<0.003$ & $<0.003$ \\
\hline \multirow{2}{*}{$100 \mathrm{~K}$} & 0.5 & 0.3 & 0.5 & 0.4 & 0.3 & 0.4 & 0.4 & 0.5 & 0.5 & 0.4 & 0.4 \\
\hline & 0.01 & 0.016 & 0.014 & 0.016 & 0.016 & 0.011 & 0.014 & 0.029 & 0.035 & 0.026 & 0.045 \\
\hline \multirow{2}{*}{$1 \mathrm{M}$} & 0.5 & 0.4 & 0.5 & 0.4 & 0.3 & 0.4 & 0.4 & 0.5 & 0.5 & 0.4 & 0.5 \\
\hline & $<0.010$ & $<0.010$ & 0.013 & 0.012 & 0.011 & 0.006 & 0.009 & 0.018 & 0.021 & 0.022 & 0.026 \\
\hline
\end{tabular}


the impedance meter is higher. Overall, the capacitances between I/O1 and I/O2 is low compared with the parasitic capacitance between the ground $\mathrm{I} / \mathrm{O}$ and a neighboring $\mathrm{I} / \mathrm{O}$ of the previously reported prototype packages based on $96 \%$ alumina with $8-\mathrm{I} / \mathrm{O}$ [2].

\begin{tabular}{|c|c|c|c|c|c|c|c|c|c|c|c|}
\hline $\mathrm{f}(\mathrm{Hz}){ }^{\mathrm{T}}\left({ }^{\circ} \mathrm{C}\right)$ & $\mathrm{T}_{\mathrm{R}}$ & 100 & 150 & 200 & 250 & 300 & 350 & 400 & 450 & 500 & 550 \\
\hline \multirow{2}{*}{120} & 0.7 & 0.6 & 0.5 & 0.4 & 0.3 & 0.4 & 0.4 & 0.6 & 0.5 & 0.6 & 0.6 \\
\hline & $<0.001$ & $<0.001$ & $<0.001$ & $<0.001$ & $<0.001$ & $<0.001$ & $<0.001$ & $<0.001$ & $<0.001$ & $<0.001$ & $<0.001$ \\
\hline \multirow{2}{*}{$1 \mathrm{~K}$} & 0.3 & 0.3 & 0.4 & 0.4 & 0.2 & 0.4 & 0.3 & 0.5 & 0.3 & 0.5 & 0.5 \\
\hline & $<0.001$ & $<0.001$ & $<0.001$ & $<0.001$ & $<0.001$ & $<0.001$ & $<0.001$ & $<0.001$ & 0.0013 & 0.001 & $<0.001$ \\
\hline \multirow{2}{*}{$10 \mathrm{~K}$} & 0.4 & 0.3 & 0.4 & 0.4 & 0.3 & 0.3 & 0.4 & 0.4 & 0.4 & 0.4 & 0.3 \\
\hline & $<0.001$ & $<0.001$ & $<0.001$ & $<0.001$ & $<0.001$ & $<0.001$ & $<0.001$ & $<0.001$ & $<0.001$ & $<0.001$ & $<0.001$ \\
\hline \multirow{2}{*}{$100 \mathrm{~K}$} & 0.3 & 0.3 & 0.4 & 0.4 & 0.2 & 0.3 & 0.3 & 0.4 & 0.4 & 0.4 & 0.3 \\
\hline & 0.005 & 0.005 & $<0.005$ & $<0.005$ & $<0.005$ & 0.005 & 0.013 & $<0.010$ & 0.014 & 0.012 & $<0.010$ \\
\hline \multirow{2}{*}{$1 \mathrm{M}$} & 0.3 & 0.4 & 0.4 & 0.4 & 0.2 & 0.3 & 0.3 & 0.4 & 0.4 & 0.4 & 0.3 \\
\hline & $<0.010$ & $<0.020$ & $<0.020$ & $<0.020$ & $<0.020$ & $<0.020$ & $<0.020$ & $<0.020$ & $<0.020$ & $<0.020$ & $<0.020$ \\
\hline
\end{tabular}

Table 2: Parasitic capacitance (upper) in unit of $\mathrm{pF}$ and $\mathrm{AC}$ conductance (lower) in unit of $\mu \mathrm{S}$ between $\mathrm{I} / \mathrm{O} 2$ and $\mathrm{I} / \mathrm{O} 3$ without a lid on. Contributions of gold wires have been subtracted.

All the conductance measurements below $0.001 \mu \mathrm{S}$ are noted as $<0.001 \mu \mathrm{S}$ in Table 1 . Basically, at $100 \mathrm{kHz}$ the conductance increases more with temperature compared with lower frequencies, and reaches $0.045 \mu \mathrm{S}$ at $100 \mathrm{kHz}$ at $550{ }^{\circ} \mathrm{C}$, consistent with material conductivity data of the alumina material reported earlier. However, the conductance at $1 \mathrm{MHz}$ are not higher than those at $100 \mathrm{kHz}$ as we expected from the conductance data of the alumina material. One of the possible reasons for this could be that the device under measurement including the gold wires connecting the package to the coaxial cables can no longer be precisely approximated as a simple parallel $\mathrm{RC}$ circuit at $1 \mathrm{MHz}$ since the impedance of the pair of I/Os is high. Overall, the parasitic conductance between $\mathrm{I} / \mathrm{O} 1$ and $\mathrm{I} / \mathrm{O} 2$ is lower than the conductance between Ground I/O and neighboring I/O of $96 \%$ alumina package previously used for high temperature SiC IC testing [2].

Table 2 shows the results of parasitic parallel capacitance (upper number) in unit of $\mathrm{pF}$ and $\mathrm{AC}$ conductance (lower number) in unit of $\mu \mathrm{S}$ between I/O2 and neighboring I/O3 (see Figure 1b). The parasitic capacitance is slightly higher at $1 \mathrm{kHz}$ and $120 \mathrm{~Hz}$ and $500{ }^{\circ} \mathrm{C}$ and $550{ }^{\circ} \mathrm{C}$ compared with those at higher frequencies and lower temperatures. The relatively high capacitance at room temperature and $100{ }^{\circ} \mathrm{C}$ at $120 \mathrm{~Hz}$ could be due to the relative higher measurement uncertainty resulted from high impedance. Compared with parasitic capacitance between a regular pair of I/Os of $96 \%$ alumina package, the capacitance between I/O2 and I/O3 of this prototype package is also significantly lower.
All the conductance measurements below $0.001 \mu \mathrm{S}$ are noted $<0.001 \mu \mathrm{S}$ in Table 2 . Basically, at frequencies at and below $100 \mathrm{kHz}$ the conductance is the highest at $100 \mathrm{kHz}$ and $450{ }^{\circ} \mathrm{C}$ and $500{ }^{\circ} \mathrm{C}$, basically consistent with conductivity data of the cofired alumina material reported earlier [4]. However, 


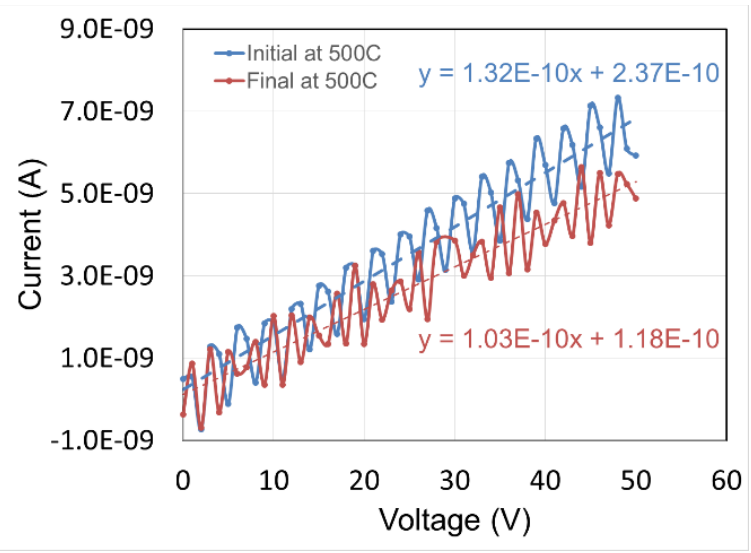

Figure 2: I-V curves measure between I/O27 -I/O28 of the co-fired package at initially at $500^{\circ} \mathrm{C}$ (blue) and 69.4 hours after (red). The noise was attributed to interference from the running oven. The dash lines are the linear fits.

\subsection{Test Results of Packaged SiC ICs}

This 32-I/O co-fired package has been tested with different kinds of SiC JFET based analog and digital integrated circuits at high temperatures. Figure 3 shows a packaged $3 \mathrm{~mm}$ x $3 \mathrm{~mm} \mathrm{SiC} \mathrm{IC} \mathrm{chip}$ mounted on an alumina printed circuit board (PCB) before high temperature test. The compatible PCB was specifically designed for high temperature test of this 32-I/O package, it also uses co-fired $\mathrm{Pt} / 92 \%$ alumina material system. The PCB measures $5.1 \mathrm{~cm} \times 5.1 \mathrm{~cm}$ x $0.64 \mathrm{~mm}$ ( 2 in. $x 2$ in. $x 25$ mil).

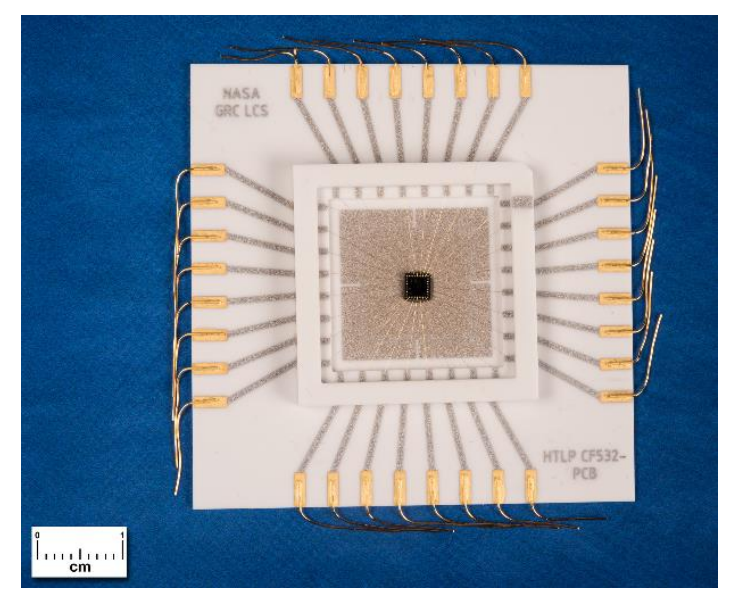

Figure 3: A test assembly of a packaged SiC JFET integrated circuit chip mounted on a co-fired $\mathrm{Pt} / 92 \%$ alumina PCB.
A SiC die was attached to the package using either lead oxide based glass mixed with Pt particles or a gold thick-film material. The Pt/glass die attach was dried at $150^{\circ} \mathrm{C}$ for ten minutes then typically heattreated at $500^{\circ} \mathrm{C}$ for two hours. Gold thick-film dieattach was also dried at $150{ }^{\circ} \mathrm{C}$ for ten minutes then heat-treated at $600{ }^{\circ} \mathrm{C}$ for two to three hours [6]. The temperature ramp rates were $3^{\circ} \mathrm{C} / \mathrm{min}$. Gold thickfilm based die attach is more suitable for testing at temperature above $600^{\circ} \mathrm{C}$. Both die attach methods are still under further development. $25.4 \mu \mathrm{m}$ (1 mil) diameter doped $\mathrm{Au}$ wires were thermo-sonically ball/wedge-bonded to electrically connect the $\mathrm{SiC}$ die to the package. $\mathrm{Cu}$ and $\mathrm{Pd}$ doped $\mathrm{Au}$ wire was used to control electro-migration under DC bias at elevated

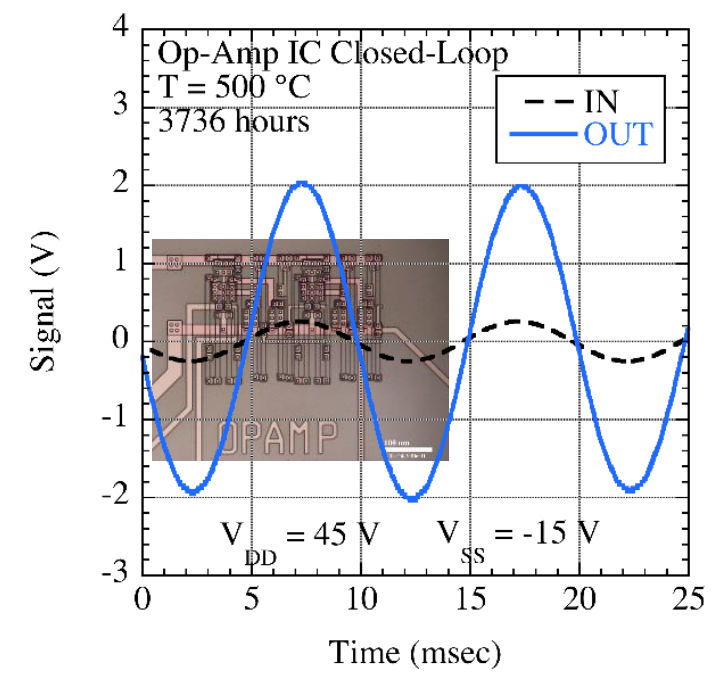

Figure 4: Input and output waveforms of a packaged OPAMP based on SiC JFETs developed at NASA GRC. The data was recorded at $500{ }^{\circ} \mathrm{C}$ after 3736 hours continuous test. The output signal was from the "_" output of the OPAMP.

temperature. Foot-long gold wires with $254 \mu \mathrm{m}$ (10 mil) diameter and glass fiber insulation sleeves were used to connect the PCB in the oven to coaxial cables to measuring instruments.

This 32-I/O package has been used to facilitate long term tests of multiple $\mathrm{SiC}$ JFET integrated circuits at $500{ }^{\circ} \mathrm{C}$. Figure 4 shows input and output waveforms of an operational amplifier (OPAMP) recorded at $500{ }^{\circ} \mathrm{C}$ after 3736 hours of continuous thermal and electrical tests [7]. The OPAMP was DC biased between $-15 \mathrm{~V}\left(\mathrm{~V}_{\mathrm{SS}}\right)$ and $45 \mathrm{~V}\left(\mathrm{~V}_{\mathrm{DD}}\right)$. The waveform in dark is the input signal and the one in blue is the output signal. The OPAMP was tested in closed loop form in which the signal gain of the circuit is determined by two on-chip $\mathrm{SiC}$ epi-resistors of ratio 
of 8 to 1 . The SiC OPAMP for high temperature applications is still under development. After 3736 hours long term testing with SiC JFET based ICs at $500{ }^{\circ} \mathrm{C}$ in thermally-static air ambient, no observable failure or degradation of any packages have been detected.

In order to assess short term survivability of both SiC ICs and the packaging system at higher temperatures, packaged $\mathrm{SiC}$ ICs were electrically tested at temperatures up to $700{ }^{\circ} \mathrm{C}$ [7]. For this test, gold thick-film material was used to attach $\mathrm{SiC}$ die to the package. Figure 5 shows the input and output waveforms of a packaged 2-input NOR gate (4-input NOR gate with inputs tied together in order to test using fewer pulse generators) based on SiC JFETs recorded after 143.5 hours of continuous test at 700 ${ }^{\circ} \mathrm{C}$. The logic " 0 " is $-10.5 \mathrm{~V}$, and logic " 1 " is $0 \mathrm{~V}$ for inputs [8]. This SiC logic gate lasted 143.5 hours at $700{ }^{\circ} \mathrm{C}$ [9]. No catastrophic packaging failure was visually observed or electrically detected during and after the test.

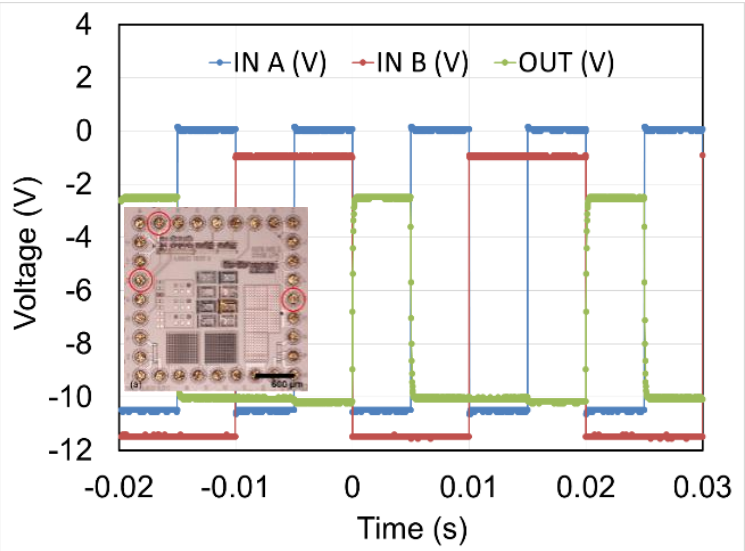

Figure 5: The inputs and output waveforms of a packaged two-inputs NOR logic gate based on $\mathrm{SiC}$ JFETs developed at NASA GRC. The data was recorded at $700{ }^{\circ} \mathrm{C}$ after 143.5 hours test [9]. The waveform of Input $\mathrm{B}$ is shifted $-1 \mathrm{~V}$ to avoid overlapping with Input A.

\section{Discussion and Conclusions}

Based on the dielectric test results of a commercial HTCC alumina material at high temperatures, a prototype 32-I/O high temperature cofired Pt/92\% alumina package for low power high temperature ICs was designed, fabricated, electrically characterized. This package was tested with $\mathrm{SiC}$ integrated circuits at $500{ }^{\circ} \mathrm{C}$, and $700^{\circ} \mathrm{C}$ for the first time. Both DC and AC electrical parasitic parameters of neighboring I/Os of this package have been characterized between room temperature and $500{ }^{\circ} \mathrm{C}$. Even at $500{ }^{\circ} \mathrm{C}$ the $\mathrm{DC}$ resistance between neighboring
I/Os is above $1 \mathrm{G} \Omega$. The parasitic capacitance between neighboring I/Os at temperatures $\mathrm{T} \leq 500{ }^{\circ} \mathrm{C}$ in the frequency range from $120 \mathrm{~Hz}$ and $1 \mathrm{MHz}$ is below $1.5 \mathrm{pF}$, and parasitic AC resistance between neighboring I/Os at temperatures $\mathrm{T} \leq 500{ }^{\circ} \mathrm{C}$ in the frequency range up to $1 \mathrm{MHz}$ is over $20 \mathrm{M} \Omega$. A PCB based on co-fired $\mathrm{Pt} / 92 \%$ alumina designed for test of this 32-I/O co-fired package has also been demonstrated. Compatible high temperature durable prototype die-attach schemes and thermo-sonic $\mathrm{Au}$ alloy wire-bonding have been demonstrated for packaging SiC JFETs based ICs using this packaging system, and packaged $\mathrm{SiC}$ ICs have been successfully tested at $500{ }^{\circ} \mathrm{C}$ for over 3736 hours. This packaging system can be used for many envisioned logic and signal conditioning high temperature ICs at temperatures up to $500{ }^{\circ} \mathrm{C}$.

This package/PCB system is fabricated using standard packaging materials and processes currently available in industry, so it can be implemented for mass production when it is needed in the future. However, further development for even better overall electrical and mechanical performances is continuing. Even though excellent wire-bonding yields have been achieved, the reliability of gold wire-bonding on the package pads can be further improved by coating a gold over layer. Therefore, an optimal Au coating process needs to be developed. A high temperature durable hermetic sealing process for this packaging system is desired to provide ICs an inert and stable environment for optimal performance and long term reliability in harsh high temperature ambient.

More long term and thermal cycling tests of this packaging system with SiC ICs are planned to further evaluate the performance as well as the reliability of this package at temperatures of $500{ }^{\circ} \mathrm{C}$ and higher.

\section{Acknowledgements}

The authors wish to gratefully acknowledge the contributions of Drs. Lawrence G. Matus and Dawn C. Emerson at the NASA Glenn Research Center. This work is supported by the NASA Transformative Tools and Technologies (TTT) project, and the NASA Planetary Instrument Concepts for the Advancement of Solar System Observations (PICASSO) programs.

\section{Reference}

1a. F. P. McCluskey, R. Grzybowski, and T. Podlesak, High Temperature Electronics, CRC Press, New York, 1997. 
1b. J. D. Cressler and H. A. Mantooth, Extreme Environment Electronics (Part I Introduction), CRC Press, Boca Raton, FL, 2013.

2. L.-Y. Chen and G. W. Hunter, " $\mathrm{Al}_{2} \mathrm{O}_{3}$ and $\mathrm{AlN}$ Ceramic Chip-level Packages for $500^{\circ} \mathrm{C}$ Operation," in Proceedings of The International Conference on High Temperature Electronics (HITEN) 2005, Paris, France, September 6-8, 2005.

3. P. G. Neudeck, S. L. Garverick, D. J. Spry, L.-Y. Chen, G. M. Beheim, M. J. Krasowski, and M. Mehregany, "Extreme Temperature 6H-SiC JFET Integrated Circuit Technology," Phys. Status Solidi A, 1-17 (2009).

4. L.-Y. Chen, "Electrical Performance of Co-Fired Alumina Substrates at High Temperatures," in Proceedings of iMAPS International High Temperature Electronics Conference (HiTEC), Albuquerque, NM, May 8-10, 2012.

\section{5. http://www.adtechceramics.com/materials}

6. P. Zheng, P. Henson, R. W. Johnson, and L.-Y. Chen, "Metallurgy for SiC Die Attach for Operation at $500^{\circ} \mathrm{C}$," Additional Conferences (Device Packaging, HiTEC, HiTEN, \& CICMT): January 2010, Vol. 2010, No. HITEC, pp. 000008-000017.

7. D. J. Spry, P. G. Neudeck, L.-Y. Chen, D. Lukco, C. W. Chang, G. M. Beheim, M. J. Krasowski, N. F. Prokop, "Processing and Characterization of Thousand-Hour $500{ }^{\circ} \mathrm{C}$ Durable 4H-SiC JFET Integrated Circuits," in Proceedings of 2016 iMAPS HiTEC, Albuquerque, NM, May 9-12, 2016.

8. Philip G. Neudeck, David J. Spry, and Liang-Yu Chen, "First-Order SPICE Modeling of ExtremeTemperature 4H-SiC JFET Integrated Circuits, " in Proceedings of 2016 iMAPS International Conference on High Temperature Electronics, Albuquerque, NM, May 9-12, 2016.

9. D. J. Spry, P. G. Neudeck, L.-Y. Chen, D. Lukco, C. W. Chang, G. M. Beheim, "Experimental Durability Testing of $4 \mathrm{H} \mathrm{SiC} \mathrm{JFET} \mathrm{Integrated} \mathrm{Circuit}$ Technology at $727^{\circ} \mathrm{C}$," in process. 